\title{
Hydrolysis of Methyl Benzoate from Piper arboreum by Naupactus bipes Beetle
}

\author{
Clécio S. Ramos and Massuo J. Kato* \\ Instituto de Química, Universidade de São Paulo, CP 26077, 05513-970 São Paulo-SP, Brazil
}

\begin{abstract}
O 3-geranil-4-hidroxibenzoato de metila (1), um novo produto natural, foi isolado das folhas de Piper arboreum (Piperaceae). O metabolismo das folhas de P. arboreum pelo besouro Naupactus bipes (Germar, 1824 - Coleoptera: Curculionidae) resultou na biotransformação de $\mathbf{1}$ para o ácido 3-geranil-4-hidroxibenzoico (2). As estruturas dos metabólitos $\mathbf{1}$ e $\mathbf{2}$ foram determinadas com base na interpretação dos dados espectroscópicos de EM, IR, RMN de ${ }^{1} \mathrm{H}$ e de ${ }^{13} \mathrm{C}$.
\end{abstract}

A new natural product was isolated from Piper arboreum (Piperaceae) leaves, the methyl 3-geranyl-4-hydroxybenzoate (1). The metabolism of $P$. arboreum leaves by Naupactus bipes beetle (Germar, 1824 - Coleoptera: Curculionidae) led to the hydrolysis of 1 to 3-geranyl-4hydroxybenzoic acid (2). The structures of both compounds were determined based on spectroscopic analysis $\left({ }^{1} \mathrm{H}\right.$ and ${ }^{13} \mathrm{C}$ NMR, MS, and IR). bipes

Keywords: Piper arboreum, prenylated benzoic acid, piperaceae, biotransformation, Naupactus

\section{Introduction}

Piper arboreum is a shrub with approximately $3 \mathrm{~m}$ height and it is popularly known as long pepper, rosemaryof-Angola or wood-of-Angola. ${ }^{1}$ P. arboreum has been used in Brazil as tea and for treatment of rheumatisms, bronchitis, colds and flu. ${ }^{2}$ A previous chemical investigation carried out on leaves of $P$. arboreum led to the identification of the amides $N$-[10-(13,14-methylenedioxyphenyl)-7(E),9(Z)pentadienoyl]-pyrrolidine, arboreumine, $N$-[10-(13,14methylenedioxyphenyl)-7(E)-pentaenoyl]-pyrrolidine and $N$-[10-(13,14-methylenedioxyphenyl)-7(E),9(E)pentadienoyl]-pyrrolidine). ${ }^{3}$ Additional investigation on leaves from allopatric species of $P$. arboreum revealed now the occurrence of a new natural product methyl 3-geranyl4-hydroxybenzoate (1) previously described as synthetic product. ${ }^{4,5}$ The function of plant secondary metabolites in mediating insect-plant interactions has been addressed in several studies ${ }^{6,7}$ and more recently, the specificity of Piper-insects relationship and the metabolism of secondary compounds by herbivorous insects has been investigated. ${ }^{8,9}$ Herein, we describe the hydrolysis of methyl benzoic acid derivative $\mathbf{1}$ to 3 -geranyl-4-hydroxybenzoic acid (2) during the digestive process of $P$. arboreum leaves by $N$. bipes beetles.

*e-mail: majokato@iq.usp.br

\section{Experimental}

Instrumentation and chromatography materials

IR spectra were measured in $\mathrm{KBr}$ pellets on a Perkin-Elmer infrared spectrometer model 1750. UV spectra were recorded on a HP 8452 A spectrophotometer using $\mathrm{MeOH}$ as solvent. LREIMS spectra were measured at $70 \mathrm{eV}$ and recorded on a VG Platform II spectrometer. ${ }^{1} \mathrm{H}$ and ${ }^{13} \mathrm{C}$ NMR spectra were recorded at 300 and $75 \mathrm{MHz}$, respectively, on Bruker DPX300 spectrometer. $\mathrm{CDCl}_{3}$ (Aldrich) was used as solvent and TMS as internal standard. Chemical shifts were reported in $\delta$ units (ppm) and coupling constants $(J)$ in Hz. Elemental analyses was obtained on a Perkin-Elmer elemental analyzer model 2400 CHN. Silica gel (Merck, 230-400 mesh) was used for column chromatographic separations, while silica gel 60 PF254 (Merck) was used for analytical $(0.25 \mathrm{~mm})$ or preparative $(1.0 \mathrm{~mm})$ TLC chromatography. HPLC analysis of extracts and pure compounds were performed on a HP-1050 instrument using a reversed phase column Supelco C18 eluted in a gradient mode starting with $\mathrm{MeOH}: \mathrm{H}_{2} \mathrm{O}(1: 1)$ raising to $100 \% \mathrm{MeOH}$ in $30 \mathrm{~min}$, with a flow rate of $1 \mathrm{~mL} \mathrm{~min}^{-1}$ and detection set at $254 \mathrm{~nm}$.

\section{Plant material}

Leaves from $P$. arboreum were collected on the Campus of the Universidade de São Paulo, Brazil (S 2333'915”; 
W 46 $\left.43^{\prime} 671^{\prime \prime}\right)$, and identified by Dr. Elsie F. Guimarães (Instituto de Pesquisas Jardim Botânico do Rio de Janeiro, Brazil). The voucher specimen (Kato-0697) was deposited in the Herbarium of Instituto de Botânica, São Paulo, Brazil.

\section{Insect material}

Specimens of N. bipes that had been feeding on Piper species were collected at the Campus of the Universidade de São Paulo in December 2000 and identified by Dr. Sérgio Antônio Vanin (Departamento de Zoologia, Instituto Biociências da Universidade de São Paulo, São Paulo, Brazil). Voucher specimen (CSR 001) has been deposited at Museu de Zoologia da Universidade de São Paulo. Adult beetles were reared in cages in the laboratory and maintained on a diet constituted of $P$. arboreum leaves under artificial light (17 h light-7 h dark) at ambient temperature $\left(24-27^{\circ} \mathrm{C}\right)$.

\section{Extraction and isolation of constituents}

Dried ground leaves (40 g) from $P$. arboreum were extracted three times with $\mathrm{CH}_{2} \mathrm{Cl}_{2}-\mathrm{MeOH}(2: 1)$ $(2 \times 500 \mathrm{~mL})$, which after concentrated in vacuum yielded $12 \mathrm{~g}$ of crude extracts. Part of the extract from leaves $(5 \mathrm{~g})$ was suspended in $\mathrm{MeOH}-\mathrm{H}_{2} \mathrm{O}$ (1:4), filtered in a bed of celite $(2 / 3, \mathrm{v} / \mathrm{v})$, then $5 \mathrm{~mL}$ of $1 \mathrm{~mol} \mathrm{~L}^{-1} \mathrm{NaCl}$ solution was added to the filtrate and the solution was extracted three times with $\mathrm{CH}_{2} \mathrm{Cl}_{2}(150 \mathrm{~mL}$ each). The organic fraction was dried over anhydrous $\mathrm{Na}_{2} \mathrm{SO}_{4}$ and concentrated in vacuum yielding $1 \mathrm{~g}$ of a chlorophyll free leaves extract. This extract was subjected to fractionation over silica gel column using hexane with increasing amounts of EtOAc as eluent yielding 30 fractions (1-30). Fraction 5 (50 mg) was subjected to prepare TLC hexane:EtOAc:AcOH (4:1:0.5), three elutions, to yield $\mathbf{1}(16 \mathrm{mg})$.

The dried feces $(400 \mathrm{mg}$ ) of $N$. bipes feeding on $P$. arboreum leaves were extracted three times with $\mathrm{CH}_{2} \mathrm{Cl}_{2}-$ $\mathrm{MeOH}$ (2:1) (60 mL each). The residue was concentrated in vacuum yielding $65 \mathrm{mg}$ of crude extract. The extract was subjected to prepare TLC using hexane:EtOAc: $\mathrm{AcOH}$ (3:6.7:0.3), three elutions, to yield $2(1.3 \mathrm{mg})$.

\section{Methyl 3-geranyl-4-hydroxybenzoate (1)}

White amorphous solid; IR $(\mathrm{KBr}) v_{\max } / \mathrm{cm}^{-1}: 3368$, 2957, 2920, 1713, 1603, 1507, 1434, 1202, 1198 and 772; LREIMS $m / z$ (rel. int.) 288 [M] (2), 175 (48), 123 (67), 69 (78) and 41 (100). Elemental analysis: C 74.59\%, H 8.45\%, O 16.96\%; calculated for $\mathrm{C}_{18} \mathrm{H}_{24} \mathrm{O}_{3}$ : C 74.97\%, $\mathrm{H} 8.39 \%$, O $16.64 \% ;{ }^{1} \mathrm{H}$ and ${ }^{13} \mathrm{C}$ NMR, see Table 1.
Table 1. ${ }^{1} \mathrm{H}$ and ${ }^{13} \mathrm{C}$ NMR (300 and $75 \mathrm{MHz}$, respectively, $\mathrm{CDCl}_{3}, J$ in $\mathrm{Hz}$ ) data for compound $\mathbf{1}$

\begin{tabular}{lll}
\hline Position & $\delta{ }^{1} \mathrm{H}$ & $\delta^{13} \mathrm{C}$ \\
\hline 1 & & 122.6 \\
2 & $7.80(1 \mathrm{H}, \mathrm{d}, 2.2)$ & 131.9 \\
3 & & 126.7 \\
4 & & 158.8 \\
5 & $6.83(1 \mathrm{H}, \mathrm{d}, 8.9)$ & 115.7 \\
6 & $7.83(1 \mathrm{H}, \mathrm{dd}, 8.9,2.2)$ & 129.7 \\
1 & $3.39(2 \mathrm{H}, \mathrm{d}, 7.15)$ & 39.7 \\
2 & $5.31(1 \mathrm{H}, \mathrm{td}, 7.15,1.18)$ & 123.7 \\
3 & & 139.3 \\
4 & $2.12(2 \mathrm{H}, \mathrm{m})$ & 26.4 \\
$5^{\prime}$ & $2.12(2 \mathrm{H}, \mathrm{m})$ & 29.7 \\
6 & $5.07(1 \mathrm{H}, \mathrm{m})$ & 121.0 \\
7 & & 132.1 \\
$8^{\prime}$ & & 25.7 \\
9 & $1.67(3 \mathrm{H}, \mathrm{s})$ & 17.7 \\
$10^{\prime}$ & $1.77(3 \mathrm{H}, \mathrm{brs})$ & 16.3 \\
$\mathrm{CO}_{2} \underline{\mathrm{CH}_{3}}$ & $1.59(3 \mathrm{H}, \mathrm{s})$ & 51.8 \\
$\underline{\mathrm{CO}_{2}}$ & $3.87(3 \mathrm{H}, \mathrm{s})$ & 167.1 \\
$\mathrm{OH}_{3}$ & & \\
\hline
\end{tabular}

3-Geranyl-4-hydroxybenzoic acid (2)

White amorphous solid; LREIMS $m / z$ (rel. int.) 274 [M] (1), 175 (16), 123 (48), 69 (85) and 41 (100). ${ }^{1} \mathrm{H}$ and ${ }^{13} \mathrm{C}$ NMR, IR in agreement with literature data. ${ }^{10,11}$

\section{Results and Discussion}

Compound 1 was isolated from extract $\left(\mathrm{CH}_{2} \mathrm{Cl}_{2}-\mathrm{MeOH}\right.$, 2:1) of $P$. arboreum leaves as a white amorphous solid. Its molecular formula was established as $\mathrm{C}_{18} \mathrm{H}_{24} \mathrm{O}_{3}$ by elemental analysis and LREIMS data. The IR spectrum indicated the presence of hydroxyl group (3368 $\left.\mathrm{cm}^{-1}\right)$, a carbonyl group $\left(1713 \mathrm{~cm}^{-1}\right)$, an aromatic ring $\left(1507,1434 \mathrm{~cm}^{-1}\right)$, and $\mathrm{C}-\mathrm{O}$ stretching band $\left(1202 \mathrm{~cm}^{-1}\right)$. The ${ }^{1} \mathrm{H}$ NMR spectrum (Table 1) of $\mathbf{1}$ showed signals corresponding to three-coupled aromatic resonance at $\delta 7.80(1 \mathrm{H}, \mathrm{d}, J$ $2.2 \mathrm{~Hz}), 6.83(1 \mathrm{H}, \mathrm{d}, J 8.9 \mathrm{~Hz})$ and $7.90(1 \mathrm{H}, \mathrm{dd}, J 8.9$ and $2.2 \mathrm{~Hz}$ ) assignable for a 1,4,5-trisubstituted aromatic ring and a signal at $\delta 5.80(1 \mathrm{H}, \mathrm{s})$ characteristic of a phenolic hydrogen; it also displayed a singlet at $\delta 3.87(3 \mathrm{H}, \mathrm{s})$ of a methyl ester group, which was confirmed by signal at $\delta_{\mathrm{C}}$ 51.8. The assignments of ${ }^{1} \mathrm{H}$ and ${ }^{13} \mathrm{C}$ NMR data signals for aromatic moiety were further confirmed by comparison to those reported for known benzoic acids analogues. The isoprenyl side chain signals were determined from COSY and HETCOR spectra. Thus, the methylene protons H-1'at $\delta 3.39(2 \mathrm{H}, \mathrm{d}, J 7.2 \mathrm{~Hz})$ were coupled to the olefinic proton $\mathrm{H}-2^{\prime}$ at $\delta 5.31(1 \mathrm{H}, \mathrm{td}, J 7.2$ and $1.8 \mathrm{~Hz})$, which in turn showed an allylic coupling to methyl group $\mathrm{H}^{-} 9^{\prime}$ at $\delta 1.77$ $(3 \mathrm{H}, \mathrm{s})$. The methine proton $\mathrm{H}^{-} 6^{\prime}$ at $\delta 5.07(1 \mathrm{H}, \mathrm{m})$ was further coupled to the methylene proton $\mathrm{H}-5^{\prime}$ at $\delta 2.12$ 
$(2 \mathrm{H}, \mathrm{m})$. The $E$ geometry of the $\Delta^{2^{\prime}, 3^{\prime}}$ double bond was established based on ${ }^{13} \mathrm{C}$ NMR data of the vinyl methyl group C-9' $(\delta 17.7)$ when compared to the chemical shifts of geraniol (C-Me, $\delta$ 17.1) and nerol (C-Me, $\delta$ 24.0), which have $(E)$ and $(Z)$ configurations, respectively. ${ }^{12}$ The assignments of aromatic carbons signals were based on comparison of ${ }^{1} \mathrm{H}$ and ${ }^{13} \mathrm{C}$ NMR data to those reported for known benzoic acid analogues. ${ }^{13}$ The linkage position of monoterpene moiety was deduced from NOESY spectrum and also by comparison of ${ }^{1} \mathrm{H}$ and ${ }^{13} \mathrm{C}$ NMR spectral data with those published for prenylated benzoic acids. ${ }^{14,15}$

$N$. bipes beetle was observed feeding on P. arboreum leaves specimens growing in a cultivation area. Thus, ten individuals of beetle were collected and maintained during three weeks on a diet constituted of fresh leaves of $P$. arboreum in order to obtain fecal material from $N$. bipes. The collected feces were dried and extracted with $\mathrm{CH}_{2} \mathrm{Cl}_{2}: \mathrm{MeOH}$ and the same procedure was carried out with not predated leaves from host plants. The fecal and leaves extracts were analyzed by HPLC and the chromatographic profile of fecal extract showed an additional major compound as compared to the chromatogram of leaves extracts. Moreover, a decrease in the relative content of $\mathbf{1}$ in the fecal extract chromatogram as compared to leaves extract chromatogram was observed and a new compound $\mathbf{2}$ could be observed (Figure 1). The fecal extract was subjected to purification steps resulting in isolation of 2. Its structure was established based on spectroscopic data of LREIMS, ${ }^{1} \mathrm{H}$ and ${ }^{13} \mathrm{C}$ NMR as the known 3-geranyl-4-hydroxybenzoic acid previously isolated from $P$. gaudichaudianum and P. elongatum. ${ }^{10,11}$

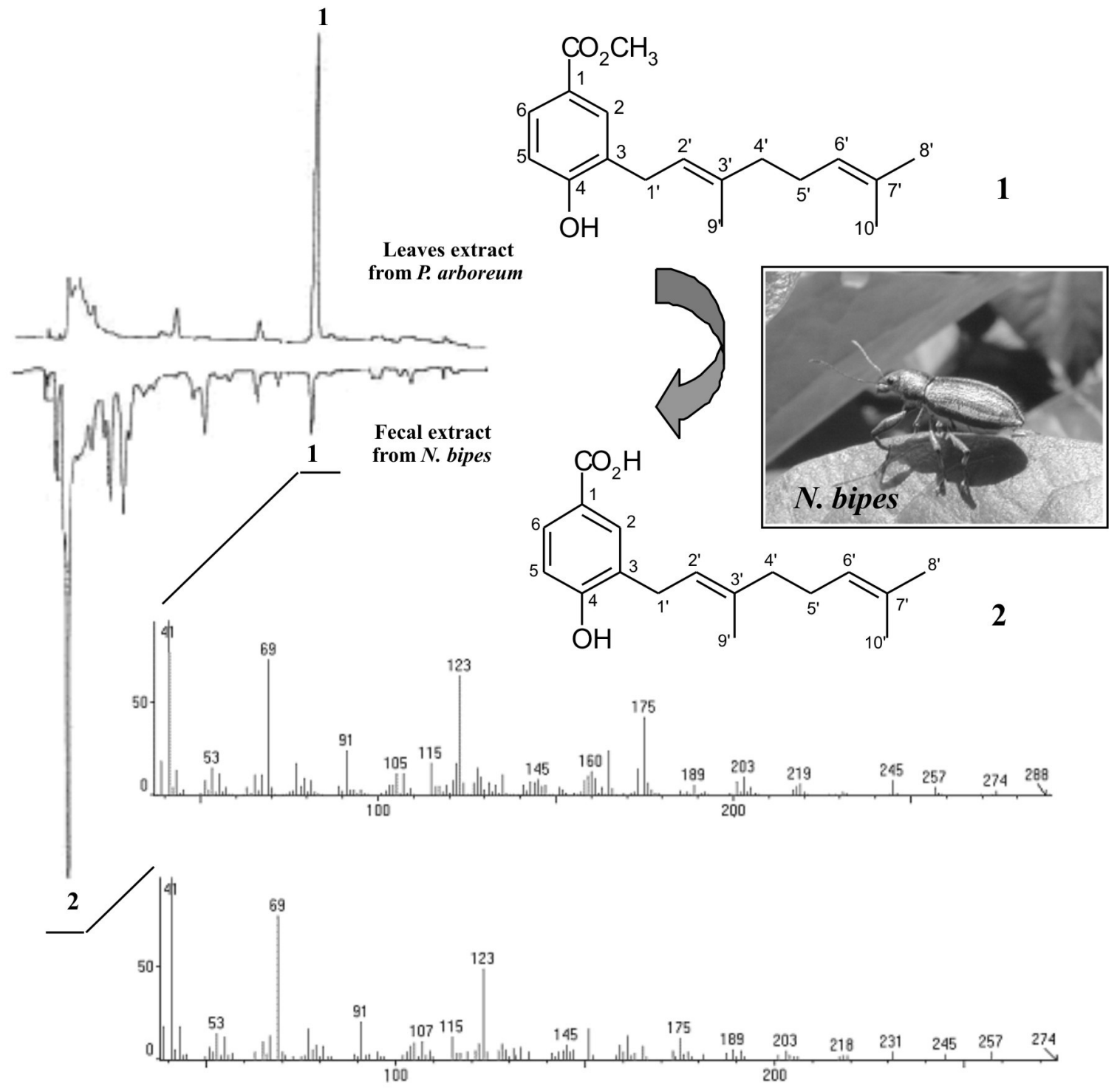

Figure 1. Chromatogram (HPLC) of extract from leaves of P. arboreum and fecal extract from $N$. bipes beetle. Mass spectra (LREIMS) of 1 and $2\left(\mathrm{C}_{18} \mathrm{H}_{24} \mathrm{O}_{3}\right.$, $\mathrm{M}=288 \mathrm{Da} ; \mathrm{C}_{17} \mathrm{H}_{22} \mathrm{O}_{3}, \mathrm{M}=274 \mathrm{Da}$, respectively). 
This finding is compatible with the formation of benzoic acid $\mathbf{2}$ as hydrolysis product of $\mathbf{1}$ during digestive process of beetle $N$. bipes. A previous investigation carried out on $N$. Bipes feeding on Piper solmsianum leaves revealed the $O$-demethylation reaction at both para positions of 3,4,5-trimethoxyphenyl ring of tetrahydrofuran lignan (-)-grandisin and no trace of benzoic acid 2 could be detected in their feces. ${ }^{9}$

\section{Acknowledgments}

This work was funded by grants provided by FAPESP and CNPq. MJK is grateful to CNPq for research fellowship. CSR thanks FAPESP for providing a scholarship.

\section{Supplementary Information}

Supplementary data are available free of charge at http:// jbcs.sbq.org.br, as PDF file.

\section{References}

1. Guimarães, E. F.; Giordano, L. C. S.; Rodriguésia 2004, 55, 21.

2. Duke, J. A.; Vasquez, R.; Amazonian Ethnobotanical Dictionary, CRC Press: Florida, 1994.

3. Silva, R. V.; Navickiene, H. M. D.; Kato, M. J.; Bolzani, V. da S.; Méda, C. I.; Young, M. C. M.; Furlan, M.; Phytochemistry 2002, 59, 521.

4. Blunt, S. B.; Chen, T-B.; Wiemer, D. F; J. Nat. Prod. 1998, 61, 1400 .
5. Inouye, H.; Ueda, S.; Inoue, K.; Matsumura, H.; Phytochemistry 1979, 18, 1301.

6. Zarbin, P. H. G.; Villar, J. A. F. P.; Corrêa, A. G.; J. Braz. Chem. Soc. 2007, 18, 1100 .

7. Marques, F. A.; Wendler, E. P.; Maia, B. H. L. N. S.; Venturab, M. U.; Arruda-Gatti, I. C.; J. Braz. Chem. Soc. 2007, 18, 1242.

8. Vanin, A. S.; Ramos, C. S.; Guimarães, E. F.; Kato, M. J.; Rev. Bras. Entomol. 2008, 52, 72.

9. Ramos, C. S; Vanin S. A; Kato, M. J.; Phytochemistry 2008, 69, 2157.

10. Lago, J. G. L.; Ramos, C. S.; Casanova, C. C. D.; Morandim, A. de A.; Bergamo, C. D.; Cavalheiro, A. J.; Bolzani, V. da S.; Furlan, M.; Guimarães, E. F.; Young, M. M. C.; Kato, M. J.; J. Nat. Prod. 2004, 67, 1783.

11. Masuoka. C.; Ono, M.; Ito, Y.; Nohara, T.; Food Sci. Technol. Res. 2003, 9, 197.

12. De Haan, J. W.; Van de Ven, L. J. M.; Org. Magn. Reson. 1973, $5,147$.

13. Moreira., D. de L.; Guimarães, E. F.; Kaplan, M. A. C.; Phytochemistry 1998, 48, 1075.

14. Baldoqui, D. C.; Kato, M. J.; Cavalheiro, A. J.; Bolzani, V. da S.; Young, M. C. M.; Furlan, M.; Phytochemistry 1999, 51, 899.

15. Orjala, J.; Erdelmeier, C. A. J.; Wright, A. D.; Rali, T.; Sticher, O.; Planta Med. 1993, 59, 546.

Received: March 17, 2008

Web Release Date: February 20, 2009

FAPESP helped in meeting the publication costs of this article. 


\section{Hydrolysis of Methyl Benzoate from Piper arboreum by Naupactus bipes Beetle}

Clécio S. Ramos and Massuo J. Kato*

Instituto de Química, Universidade de São Paulo, CP 26077, 05513-970 São Paulo-SP, Brazil

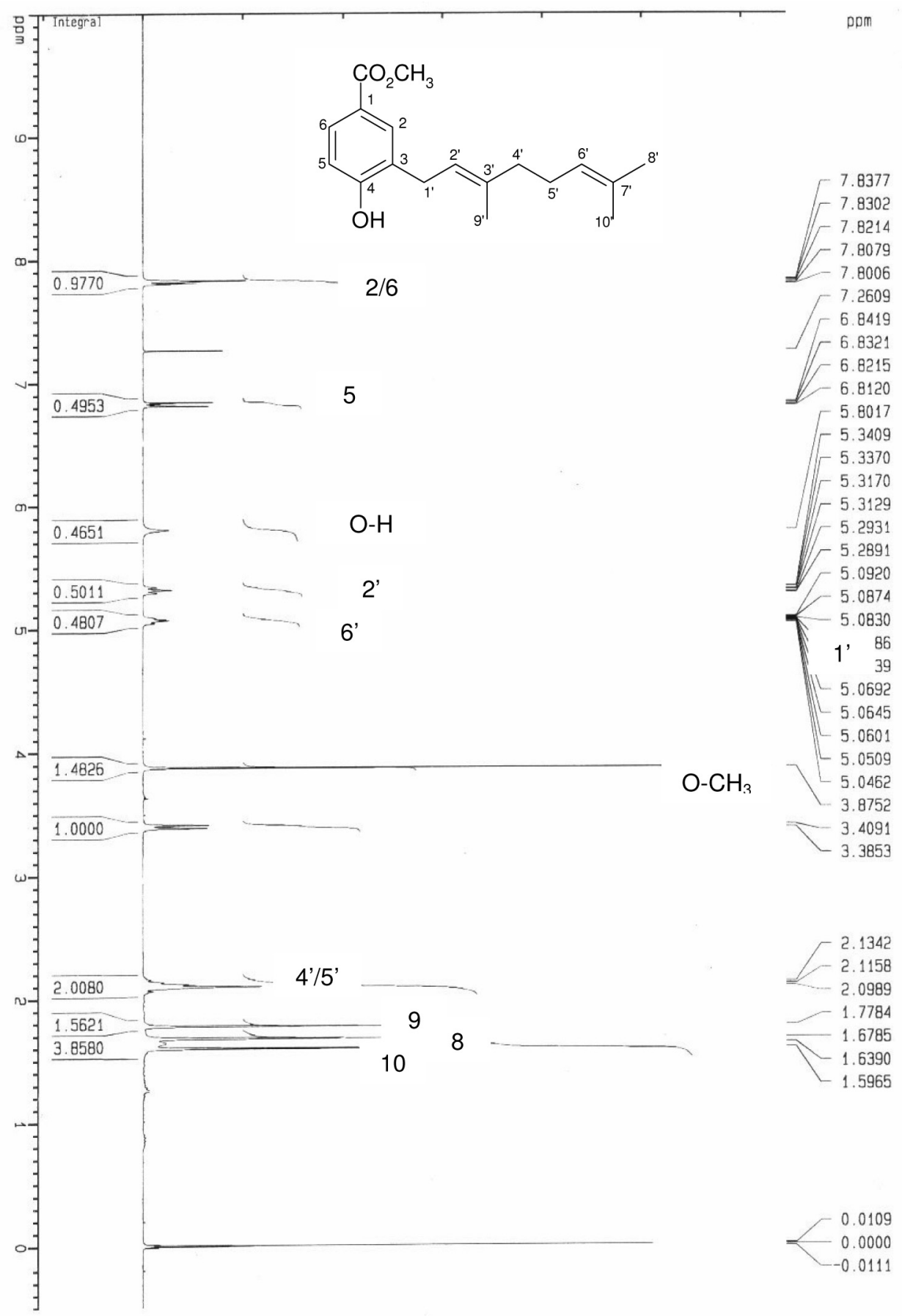

Figure S1. 'H NMR spectra of compound 1 (300 MHz, CDCl3, TMS).

*e-mail: majokato@iq.usp.br 


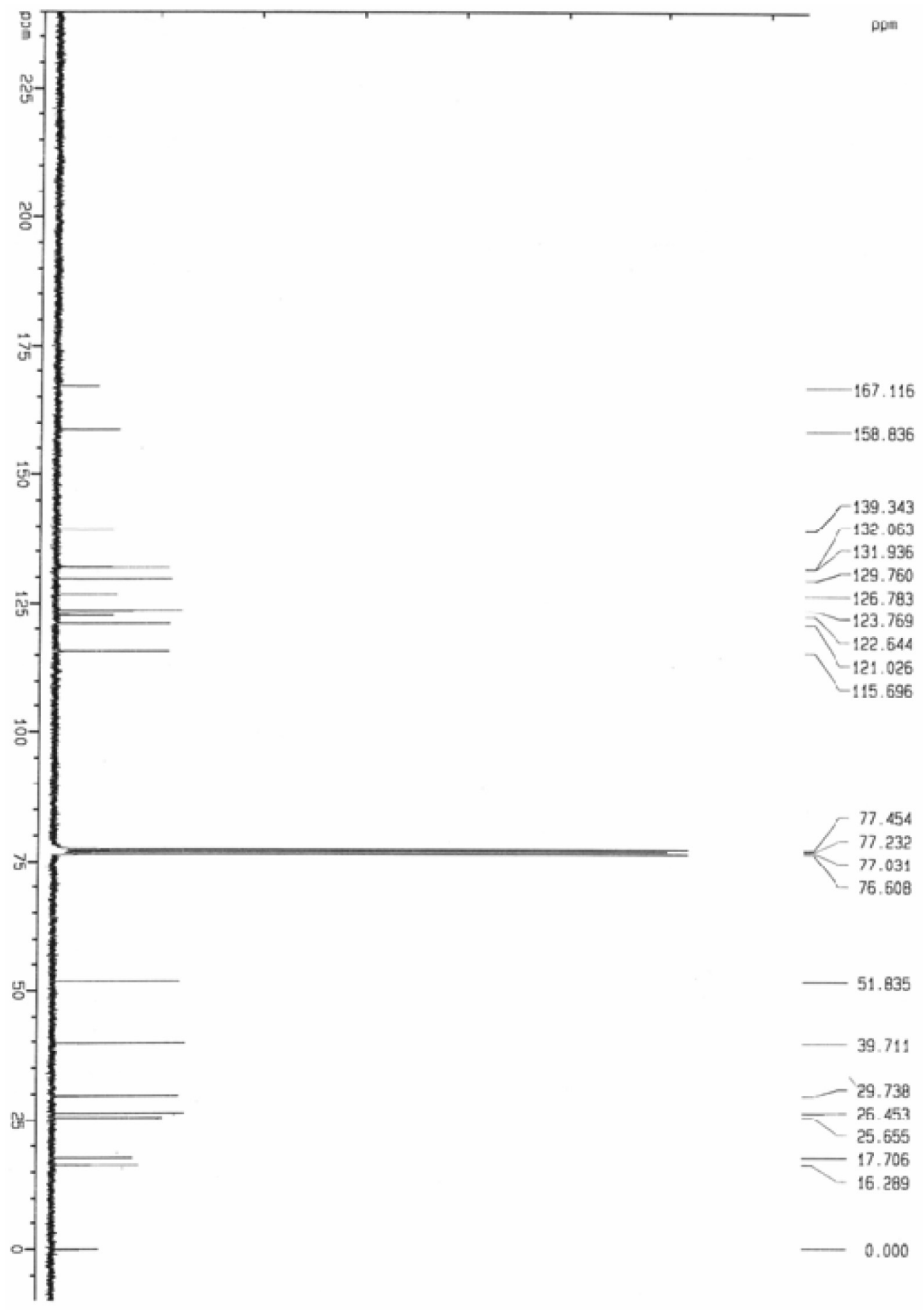

Figure S2. ${ }^{13} \mathrm{C}$ NMR spectra of compound $1(75 \mathrm{MHz}, \mathrm{CDCl} 3, \mathrm{TMS})$. 


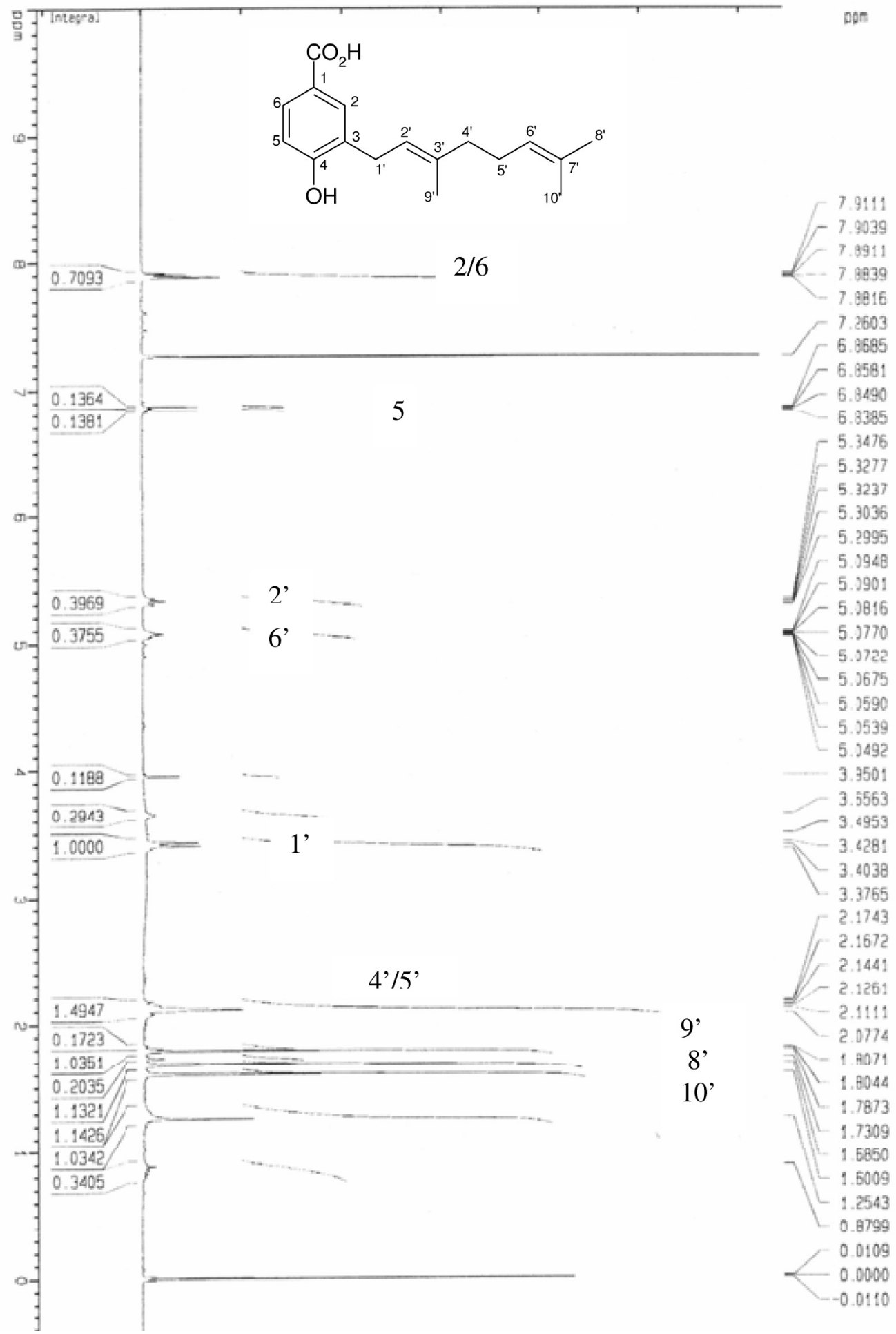

Figure S3. ${ }^{1} \mathrm{H}$ NMR spectra of compound 2 (300 MHz, CDCl3, TMS). 


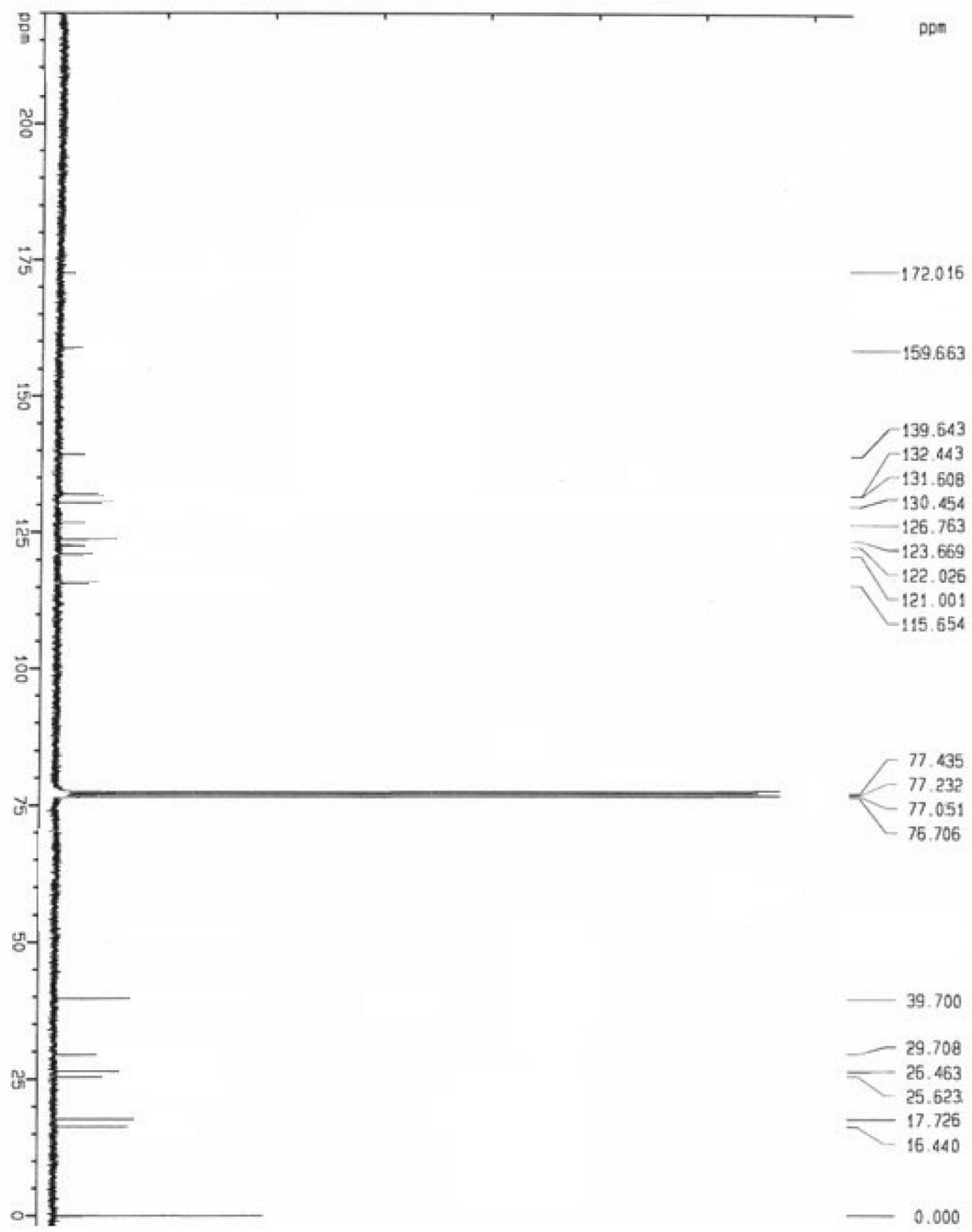

Figure S4. ${ }^{13} \mathrm{C}$ NMR spectra of compound 2 (75 MHz, CDCl3, TMS). 